\title{
Functional and Aesthetic Evaluation of Expanded Applications of Conservative Management of Fingertip Amputations
}

\author{
ASHRAF HUSSIEN ELGHAMRY, M.D.; WALEED ALDABAANY, M.D.; SHERIF MAHER, M.D. and \\ ABDULRAHMAN ALNAKEEB, M.Sc. \\ The Department of General Surgery, Plastic \& Reconstructive Unit, Faculty of Medicine, Fayoum University, Fayoum, Egypt
}

\begin{abstract}
Background: Fingertip amputations are the most common type of amputation injury in the upper extremity. Treatments available cover a broad range of techniques, surgical and conservative. Although there is no consensus on how these injuries should be treated, the goals of treatment should include minimization of pain, optimization of healing time, preservation of sensibility and length, prevention of painful neuromas, avoidance or limiting of nail deformity, minimization of time lost from work, and provision of an acceptable cosmetic appearance.
\end{abstract}

Patients and Methods: We have prospectively studied 20 patients with fingertip amputations of all ages. Daily simple non adherent non occlusive dressing, paraffin-impregnated gause, with an ointment initially for debridement then for healing was used. We used pinch gauge, finger goniometer, caliper and compass to measure pinch tip strength, distal phalanx range of motion and 2 point discrimination distance, respectively.

Results: The mean age was $(33 \pm 17.3)$ years old. The mean healing time was $(36.4 \pm 5.8)$ days and mean time off work was $(11.6 \pm 7.6)$ days. As regards sensibility $30 \%$ complain numbness, $35 \%$ had hyper-sensibility, and 35\% show normal sensibility. As regards two point discrimination in the corresponding healthy fingertip, the mean distance was $(4.7 \pm 1.5)$ $\mathrm{mm}$, versus $(8.6 \pm 2.5) \mathrm{mm}$ in amputated fingertip. There was no tenderness, cold intolerance, joint stiffness, neuroma or disability. 50\% expressed good aesthetic results, $40 \%$ of patients were accepted, and $10 \%$ had poor aesthetic results.

Conclusion: The functional outcome was good, as there were no tenderness, cold intolerance, joint stiffness, neuroma or disability. Although, longer healing time, time off work was generally acceptable. Irrespective of that a $35 \%$ of patients have hyper-sensibility and 30\% complained of numbness, there were no significant bad impact on the function and early return to work. Aesthetically, hook nail deformity was the only cause of poor aesthetic results. However, conservative management of fingertip amputations using simple daily dressing changes, provides good and acceptable results outweighs the poor results.

Key Words: Fingertip amputation - Fingertip injury - Secondary healing - Conservative management of fingertip injury.

\section{INTRODUCTION}

A fingertip amputation is defined as any amputation of the soft tissue, nail or bony element distal to the dorsal and volar skin creases at the distal interphalangeal joint and insertions of long flexor and extensor tendons of a finger or thumb [1].

Fingertip amputations are the most common type of amputation injury in the upper extremity. These injuries are either seen in the emergency room or in an office setting. These lesions are very frequent and require precise wound care for optimal results. Treatment of fingertip injuries is a continuous focus of controversy among hand and orthopedic surgeons [2].

Goals of treatment should include minimization of pain, optimization of healing time, preservation of sensibility and length, prevention of painful neuromas, avoidance or limiting of nail deformity, minimization of time lost from work, and provision of an acceptable cosmetic appearance [1].

The treatment of fingertip amputations is controversial and so, many treatment options are available. These treatment options are either conservative management or surgical treatment.

Despite ongoing publications of new flaps for fingertip reconstruction, there is a paucity of evidence to support improved healing and function in a surgically reconstructed fingertip compared to conservative wound management [3].

Previously, authors advocated that defects $>1 \mathrm{~cm}$ should be closed with local flaps. However, recently, authors reported that healing by secondary intention with dressing changes is one of the best options for a tip amputation without exposed bone and will be most applicable for wounds with skin 
loss of $1.5 \mathrm{~cm}$ or less; healing will occur by reepithelialization over 3 to 4 weeks with return of normal sensation and two-point discrimination. If there is additional loss of subcutaneous tissue of similar size, it may take 1 to 2 months to heal by secondary intention [4].

Some have expanded the application of the conservative management to include larger wounds up to $2-3 \mathrm{~cm}^{2}$ can heal by secondary intention without bone, tendon or neurovascular structures exposure, this is at the expense of longer healing time [5].

In this study we will evaluate the functional and aesthetic outcome of conservative management of fingertip amputations of variable defect sizes and the expanded application to include defects $\geq 2-3 \mathrm{~cm}^{2}$ even with exposed bone of variable lengths, surrounded by soft tissue at any side of its circumference, but not skeletonized.

\section{PATIENTS AND METHODS}

This prospective study was approved by the Research Ethical Committee of Faculty of Medicine, Fayoum University and conducted on 20 patients presented to the Emergency Department of Fayoum University Hospital, complaining of fingertip amputations, in the period from March 2018 to May 2019.

All ages were included in the study, patients with isolated fingertip amputation, not associated with other trauma and fingertip amputations within 24 hours of injury were also included.

Multi-trauma patient, diabetic uncontrolled patients with polyneuropathy, defects with skeletonized bone, not surrounded by soft tissues at any side of its circumference and fingertip amputations with exposed tendon were excluded from the study.

On admission, adequate history taking, thorough physical examination and X-rays were taken to exclude associated hand injury.

Daily simple non adherent dressing, paraffinimpregnated gauze, with an ointment initially for debridement then for healing was used.

We have measured the defect surface area, length of bone exposed, length of bone trimmed.

We used pinch gauge, finger goniometer, caliper and compass to measure pinch tip strength, distal phalanx range of motion and 2 point discrimination distance, respectively.
We have evaluated sensibility, tenderness, cold intolerance, development of neuroma and disability.

Aesthetic outcome, healing time and time off work were also noted.

Follow-up period was at least 9 months after healing occur.

Data was expressed as mean \pm Standard Deviation (SD) or number (\%).

The $p$-value $\leq 0.05$ was considered the cut-off value for significance.

\section{RESULTS}

The mean age was $(33 \pm 17.3)$ years old. The patients were 16 males (80\%) and 4 females (20\%). $95 \%$ of patients had crushed amputation, the left hand was affected in $70 \%$ of patients, the middle finger is the most affected finger (35\%) followed by the thumb $(20 \%)$.

The mean surface area of amputated fingertips was $(3.9 \pm 1.6) \mathrm{cm}^{2}$, all cases had bone exposed with mean length of $(4.1 \pm 1.6) \mathrm{mm}, 10 \%$ of them had been trimmed with mean length of trimming was $(2.5 \pm 0.71) \mathrm{mm}$. The mean healing time was (36.4 \pm 5.8$)$ days and mean time off work was (11.6 \pm 7.6) days.

As regards sensibility $30 \%$ complain numbness, $35 \%$ had hyper-sensibility, and $35 \%$ show normal sensibility.

As regards two point discrimination in the corresponding healthy fingertip, the mean distance was $(4.7 \pm 1.5) \mathrm{mm}$, versus $(8.6 \pm 2.5) \mathrm{mm}$ in amputated fingertip with a statistical significance difference with $p$-value $<0.05$ in two points discrimination in healthy and amputated fingertips.

The mean pinch tip strength was $(2.18 \pm 1) \mathrm{kg}$ versus $(3.5 \pm 1.6) \mathrm{kg}$ in contralateral normal fingertip. There is statistical significance difference with $p$-value $<0.05$ in pinch tip strength in contralateral healthy and amputated fingertip.

The mean degree of joint flexion was (124.5 \pm $15.8)^{\circ}$ and mean degree of joint extension was $(11.5 \pm 4.3)^{\circ}$. The mean normal degree of active flexion of the DIP joint in the normal contralateral finger was $\left(118.5^{\circ}\right)$, range from $\left(105^{\circ}-140^{\circ}\right)$, the mean normal degree of active extension of the DIP joint in the normal contralateral finger was $\left(10.75^{\circ}\right)$, range from $\left(5^{\circ}-20^{\circ}\right)$. 
There was no tenderness, cold intolerance, joint stiffness, neuroma or disability in all patients.

$45 \%$ of patients had hook nail deformity, followed by $10 \%$ complained amputated nail and nail bed, and $5 \%$ had short nail, versus $40 \%$ show normal nail with no deformity.

$50 \%$ of patients expressed good aesthetic results, $40 \%$ of patients had accepted aesthetic results, and $10 \%$ had poor aesthetic results.
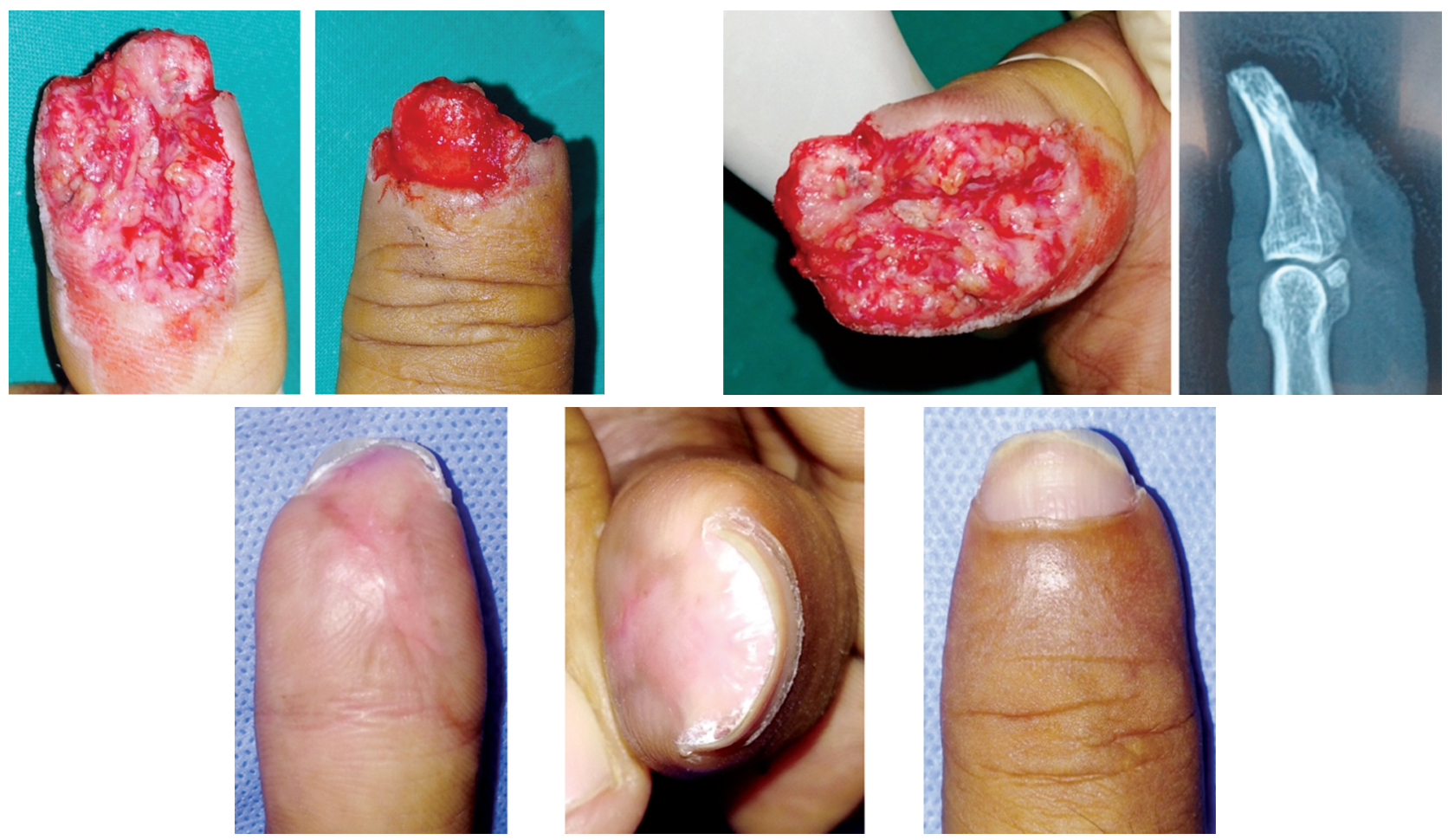

Fig. (1): Before and 9 months after conservative treatment of amputated right thumb finger tip.
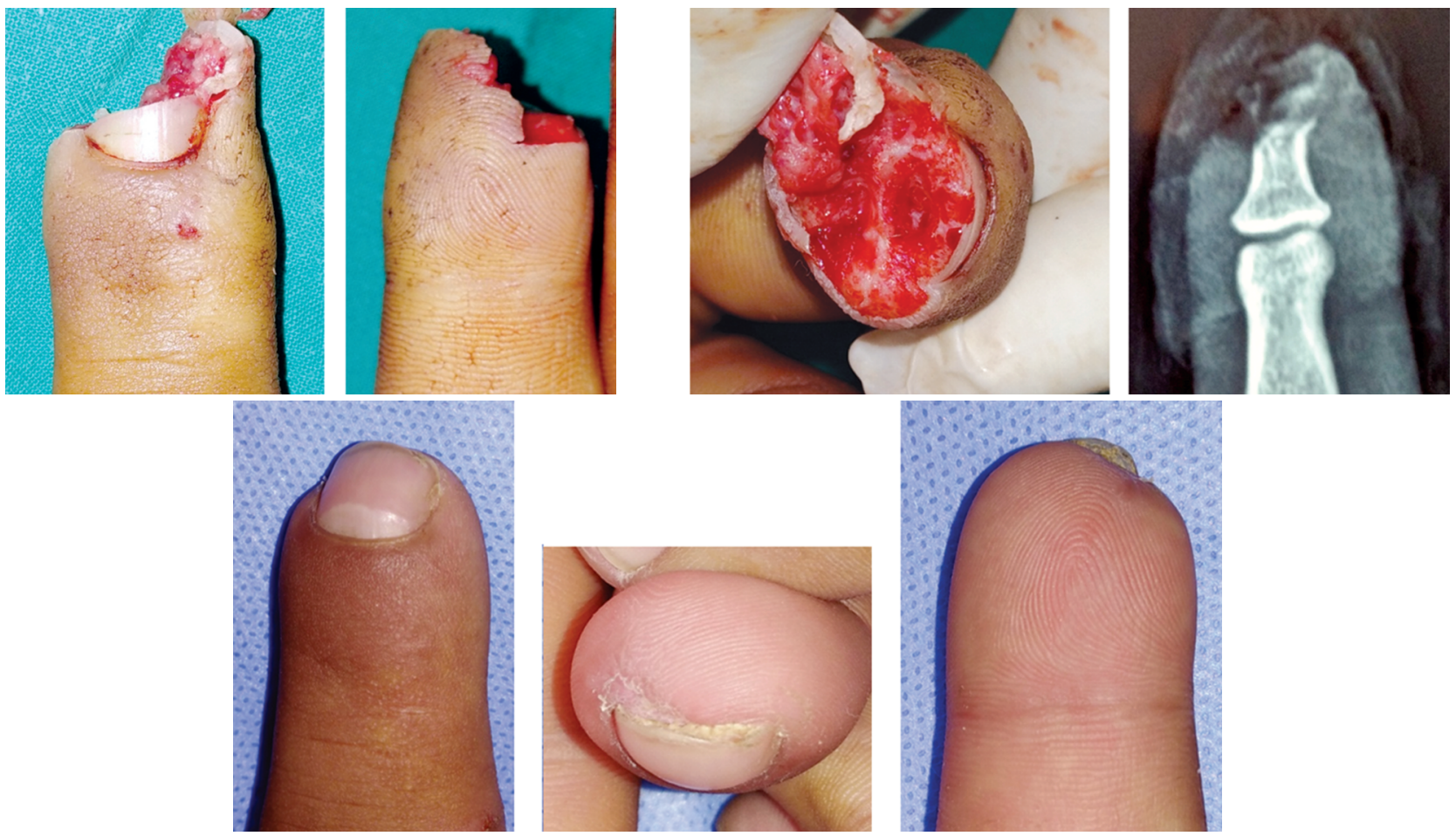

Fig. (2): Before and 10 months after conservative treatment of amputated left index finger tip. 

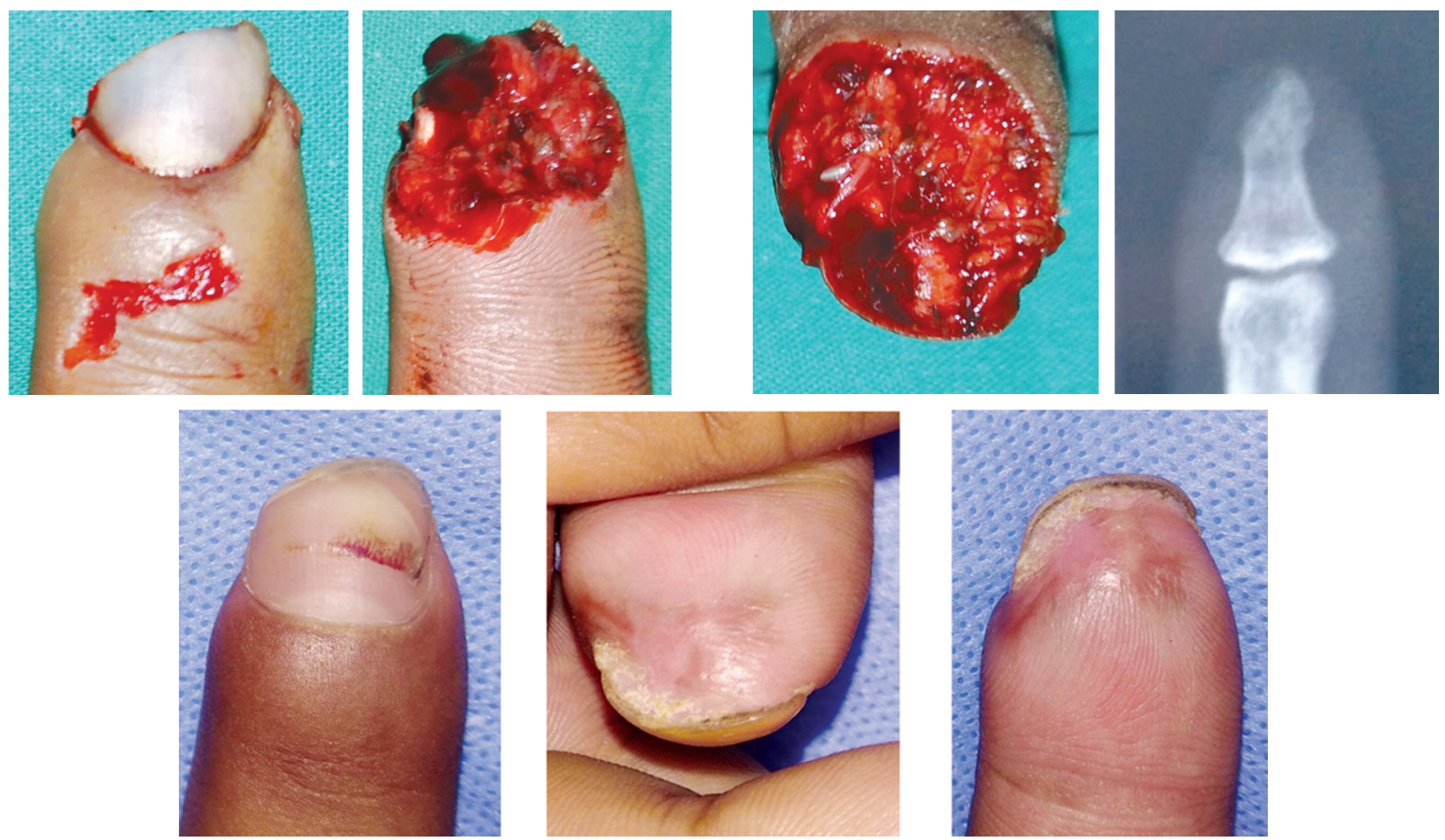

Fig. (3): Before and 9 months after conservative treatment of amputated left index finger tip.
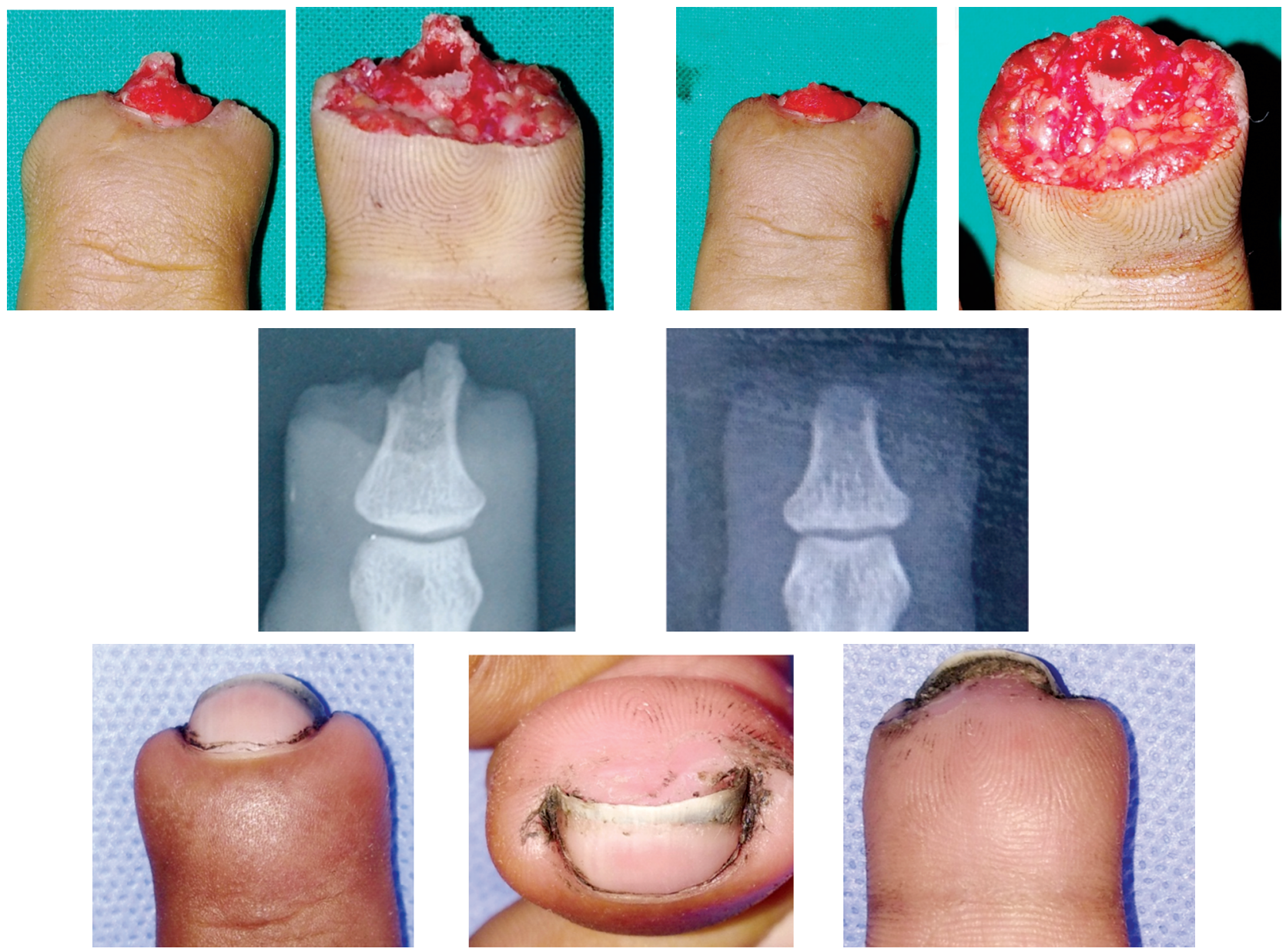

Fig. (4): Before and 9 months after conservative treatment of amputated right ring finger tip. 


\section{DISCUSSION}

Fingertip amputations are among the most common traumatic injuries that present for acute care. The fingertip is a specialized structure that permits fine motor activity and precise sensation and contributes to hand aesthetics [6].

A reasonable treatment strategy for a fingertip amputation should consider both cosmetic and functional outcome. The conservative approach requires no surgical skill, has a low risk for complications, and is likely to result in a sensate, nontender, and cosmetically appealing finger [7].

In the literatures, no clear definition of fingertip and thumb tip defects can be found, mostly the defects are defined as small or large, but there are classifications that describe the involved structures as the nail, pulp, or bone [8].

Champagne et al., in a systematic review found that healing by secondary intention is a preferred treatment for many authors, because it provides the best possible functional and cosmetic result, with minimal risk of iatrogenic complications [7].

We have evaluated the functional and aesthetic outcome because it is challengeable to treat a wider defects of fingertip amputations with exposed bone conservatively with only simple dressing changes.

Fingertip amputations with skeletonized bone, except if the patient preferred trimming and conservative management over surgical reconstruction, were excluded from the study; because we felt that in this situation no soft tissue to creep and cover it.

We meant with skeletonized bone, not surrounded by soft tissues at any side of its circumference.

Surface area calculated as the longest length head-to-toe and longest width side-to-side, perpendicular to length. Keast et al., reported that research indicates that this method in wound measurement is indeed the more valid and reliable method compared with other ruler-based methods [9].

The mean surface area of amputated fingertip was $(3.9 \pm 1.6) \mathrm{cm}^{2}$. In the contrary, in the literatures, no clear definition of fingertip and thumb tip defects can be found, mostly the defects are defined as small or large, and the litratures who mentioned the defet size in conservative management of fingertip amputations were $<1 \mathrm{~cm}^{2},>1 \mathrm{~cm}^{2},<1.5 \mathrm{~cm}^{2}$ and the expanded application was for defect size $>1.5 \mathrm{~cm}^{2}[3]$.
A study conducted by Ipsen et al., included defects more than $1 \mathrm{~cm}^{2}$ in adults and more than $0.5 \mathrm{~cm}^{2}$ in children, with no tendon or joint exposed.

Amer's study in 2008, the mean surface area of the defect was $1.6 \mathrm{~cm}^{2}$ (range $0.5-2.2 \mathrm{~cm}^{2}$ ) [10,11].

Weichman and his colleagues reported that average defect size allowed to heal by secondary intention was $1.75 \mathrm{~cm}^{2}$, all without exposed bone [12].

Some have expanded the application of the conservative management to include larger wounds up to $2-3 \mathrm{~cm}$ can heal by secondary intention without bone, tendon or neurovascular structures exposure [5].

In our thesis, all cases had bone exposed with mean length of $(4.1 \pm 1.6) \mathrm{mm}, 10 \%$ of them had been trimmed with mean length of trimming was $(2.5 \pm 0.71) \mathrm{mm}$.

Only 2 cases had been trimmed; the $1^{\text {st }}$ one was $4 \mathrm{~mm}$ exposed bone, we trimmed $3 \mathrm{~mm}$, left $1 \mathrm{~mm}$. It was skeletonized, one case only in our study, and patient refused flap coverage and preferred conservative management.

The $2^{\text {nd }}$ one was with $5 \mathrm{~mm}$ exposed bone, $2 \mathrm{~mm}$ trimmed, $3 \mathrm{~mm}$ left, it was a sharp bony spicule in agreement with Champagne et al., previously discussed in our review.

In the rest of cases, no more trimming were done; to avoid shortening and we felt that soft tissue around will creep.

In the contrary, most literatures of conservative management of fingertip amputations agreed on that conservative without bone exposed, some treated conservatively with exposed bone in children only Allen treated conservatively in adult with exposed bone and minimal trimming done, but did not mention how much bone exposed and how much he trimmed [13].

Some authors classified the defect $>1.5 \mathrm{~cm}^{2}$ with bone exposed as a candidate for semi occlusive dressing [14,15].

About bone trimming, some mentioned only $1-2 \mathrm{~mm}$ [6]. Some did not mention, and reported to trim the bone until leave soft tissue cover $>3 \mathrm{~mm}$ and trim the nail bed $2 \mathrm{~mm}$ proximal to the bone in order to avoid hook nail deformity [16].

Some mentioned trimming only for sharp specules 1-3mm [7]. 
In our thesis, we measured the amount of bone exposed and length of trimming.

Only $15 \%$ of our patients had nail bed lacerations. We had repaired them in order to avoid nail deformity, this was with agreement with Lee et al. [17].

In this study, $20 \%$ associated distal phalangeal fractures, 1 angulated and in place, other comminuted and the remaining 2 were fissure fractures. As reported by Yeo et al., we prescribed analgesia and protection with a suitable cap or aluminium splint for 2-3 weeks. Repair of the nail bed was enough to stabilizes the fractures [18].

The mean pinch tip strength of our patients was $(2.18 \pm 1) \mathrm{kg}$. Compared to the mean pinch tip strength in the contralateral healthy fingertip was $(3.5 \pm 1.6) \mathrm{kg}$. This may be due to initial hypersensitivity and more proximal amputations.

In our study, there was no statistically significant difference with $p$-value $>0.05$ in tip pinch in different gender and side of lesion.

On the other hand there was statistically significant difference with $p$-value $<0.05$ in tip pinch in healthy and amputated fingertip with low mean among amputated finger.

In contrast, most studies reported no change in pinch grip strength except in the very proximal fingertip injuries [13,19].

In agreement with them, proximal injuries, Allen III and IV, were $90 \%$ of our cases, showed apparent decrease in pinch tip strength.

The mean healing time was $(36.4 \pm 5.8)$ days. The most commonly reported mean time to complete healing using conservative wound care alone was 4 weeks, small defects $(<1 \mathrm{~cm})$ with no bone involvement were frequently healed within 2 weeks [20].

The mean healing time reported by Ipsen was 25 days defect was $>1 \mathrm{~cm}^{2}$ no exposed bone. Lee et al., the mean healing time was 32 days e defect size $<1 \mathrm{~cm}$ with exposed bone [3].

Amer, reported that healing time was 29 days (range 21 to 45 days) in fingertip amputations of mean defect sizes $1.6 \mathrm{~cm}^{2}$ without exposed bone $[11,21]$.

Healing time, in literatures used the semi occlusive dressing, was as follows: Mennen and Wise in a series of 200 fingertip amputations found a healing time ranging from 20 to 30 days and good functional recovery. Hoigné et al., in 2014, the treatment duration with an average of 6.5 weeks may seem relatively long. The same type of injury treated with the same method by Quell et al., in 1998 had a treatment period of 49 days and Richter in 2010 described a duration of 6 weeks. This is a remarkable consistency between the three studies.

In our study, $45 \%$ of patients had hook nail deformity, followed by $10 \%$ complained of amputated finger nail and nailbed, and 5\% had short nail, versus $40 \%$ show normal nail with no deformity. Patients who had hook nail deformity were 9 patients. Only 2 of them exposed for bone trimming, the remaining 7 patients underwent no trimming.

This is may be due to the wound contraction occurs with 2ry healing, some of cases were proximal and we didn't excise the nail bed proximal to the exposed bone in other cases.

According to literatures, the main residual deformity with secondary healing is the hook nail or parrot beak deformity, which occurs mainly in the most proximal injuries [13,20].

As regards sensibility $35 \%$ show normal sensibility, while $35 \%$ had hyper-sensibility and $30 \%$ complained of numbness.

Altered sensibility, hypersensitivity and numbness, usually occurs early after healing but is usually transient. It may be due to the relatively larger defect surface area $(3.9 \pm 1.6) \mathrm{cm}^{2}$. It may improve within 12 months after healing. Amer in 2008, hypersensitivity was noticed in 12 fingers (35.3\%) after 3 months. After 12 months no hypersensitivity was noticed in any fingertip [11,21].

Ipsen et al., noticed numbness in (36\%) of his cases [10].

In our study, patients had neither cold intolerance nor tenderness, even in cases with highest length of exposed bone. This may be due to the adequate soft tissue and glabrous skin pulled over the exposed bone in the process of 2ry intension.

Patients were asked according to the Cold Intolerance Symptom Severity (CISS) questionnaire, and did not complain from any symptom related to low temperature, such as during cold weather [22].

In the contrary, Amer et al., reported that cold intolerance was detected in 9 fingertips $(27.3 \%)$ after 3 months and only in 2 fingers $(6.1 \%)$ after one year [21]. 
Many literatures reported that the highest incidence of cold intolerance was $86 \%$ at 2 months, but all reports showed a decreasing incidence with time. Cold intolerance frequently resolved by 1 year and caused disability in only a small minority of patients. Ipsen et al., noticed that the main later complaints were intolerance of cold in $(36 \%)$ of cases [3].

Cold intolerance tends to be low in conservative management of fingertip amputations but more common in proximal injuries.

In the current study, the mean time off work was (11.6 \pm 7.6$)$ days. This was a relatively shorter period than other literatures, because we have encouraged early return to work, provided keeping the wound away from any injurious things or dirt. The patients were lost more time off work justify this because of fear from them to use their affected digits.

Allen reported that the mean time off work was 18 for distal amputations and 26 for proximal. Lee et al., reported 30 days time off work [3].

Weichman et al., followed 100 fingertips prospectively. Sixty-four percent of patients healed secondarily, $18 \%$ underwent operative intervention, and $18 \%$ were lost to follow-up. Patients requiring surgery were more likely to have a larger defect and exposed bone. They also had a longer average return to work time (4.33 weeks) when compared with the secondary healing group (2.98 weeks) [12].

Assessing the aesthetic result is a crude, subjective assessment and determined according to the patient's own culture and standards.

In our study $50 \%$ had been satisfied and expressed their aesthetic results as good, $40 \%$ of patients were acceptable, and $10 \%$ had poor aesthetic results. Patients justify their acceptable and poor aesthetic results, because of hook nail deformity.

In agreement with our results, residual nail deformity was the usual cause of aesthetic dissatisfaction in systematic review of 1592 fingertip amputation [3].

Douglas in 1972 reported good aesthetic outcome and accompanying restoration of some of the length and thickness of the pulp of 29 children treated conservatively. Small defect size without bone exposed in children may justify his results [7].
Amer reported good cosmetic outcome in 26 fingertips (76.47\%) out of 34 cases. A relatively small defect size without bone exposed may justify his results [11].

In our thesis, neither of cases showed neuroma, nor disability. Although neuroma-type problems can occur with secondary healing, they are rare [3].

Hoigné et al., reported that only one patient developed a clinically diagnosed neuroma, which was treated with desensitization program [22].

\section{Conclusion:}

Conservative management of fingertip amputations using repeated dressings is an effective, simple and good option for treatment of fingertip amputations with bone exposure of variable lengths up to $(4.1 \pm 1.6) \mathrm{mm}$, even with relatively larger surface area of the defect, up to $(3.9 \pm 1.6) \mathrm{cm}^{2}$, provided that presence of adequate soft tissue around and the bone not skeletonized.

The functional outcome was good, as there were no tenderness, cold intolerance, neuroma or disability. Although longer healing time, time off work was generally acceptable.

There were statistically significant difference with $p$-value $<0.05$ in pinch tip strength and two point discrimination distance in healthy and amputated fingertips.

Hook nail deformity was the only cause of poor aesthetic results. However, conservative management of fingertip amputations using simple daily dressings provides good and acceptable results outweigh the poor results.

\section{REFERENCES}

1- Peterson S.L., Peterson E.L. and Wheatley M.J.: Management of fingertip amputations. The Journal of hand surgery, 39 (10): pp. 2093-101, 2014.

2- Rozmaryn L.M.: Distal phalangeal and fingertip injuries. Fractures and dislocations of the hand and fingers. Chicago: American Society for Surgery of the Hand, 55, 2013.

3- Krauss E.M. and Lalonde D.H.: Secondary healing of fingertip amputations: A review. Hand, 9 (3): pp. 282-8, 2014.

4- Kakar S.: Digital Amputations'. In: S. Wolfe; N Hotchkiss, W.C Pederson, S. H Kozin and M.S Cohen, eds., Green's operative hand surgery, $7^{\text {th }}$ ed., Elsevier, Philadelphia, PA: pp. 1708-12, 2017.

5- Mailey B. and Neumeister M.W.: The fingertip, nail plate and nail bed: Anatomy, repair, and reconstruction', adapted by J. Chang, and P.C. Neligan (eds), Plastic Surgery EBook: Volume 6: Hand and Upper extrimity, $4^{\text {th }}$ edn, 
(Expert Consult-Online) (Vol. 6). Elsevier Health Sciences., pp. 134-6, 2018.

6- Lemmon J.A., Janis J.E. and Rohrich R.J.: Soft-tissue injuries of the fingertip: Methods of evaluation and treatment. An algorithmic approach. Plastic and reconstructive surgery, 122 (3): pp. 105e-117e, 2008 .

7- Champagne L., Hustedt J.W., Walker R., Wiebelhaus J. and Nystrom N.A.: Digital tip amputations from the perspective of the nail. Advances in Orthopedics, 2016.

8- Germann G., Rudolf K.D., Levin S.L. and Hrabowski: Fingertip and thumb tip wounds: Changing algorithms for sensation, aesthetics, and function. The Journal of Hand Surgery, 42 (4): pp. 274-84, 2017.

9- Langemo D., Anderson J., Hanson D., Hunter S. and Thompson P.: Measuring wound length, width, and area: Which technique? Advances in skin \& wound care, 21 (1): pp. 42-5, 2008.

10- Ipsen T., Frandsen P.A. and Barfred T.: Conservative treatment of fingertip injuries. Injury, 18 (3): pp. 203-5, 1987.

11- Amer T.A.: Conservative Management versus Full Thickness Skin Grafting in Treating Finger Tip Injuries without Bone Exposure. Kasr El Aini Journal of Surgery, 9 (3): p. 29, 2008.

12- Weichman K.E., Wilson S.C., Samra F., Reavey P., Sharma S. and Haddock N.T.: Treatment and outcomes of fingertip injuries at a large metropolitan public hospital. Plastic and Reconstructive Surgery, 131 (1): pp. 107-12, 2013.

13- Allen M.J.: Conservative management of finger tip injuries in adults. Hand, (3): pp. 257-65, 1980.
14- Mennen U. and Wiese A.: Fingertip injuries management with semiocclusive dressing. Journal of Hand Surgery, 18 (4): pp. 416-22, 1993.

15- McClellan W.T. and Kurian S.: The IV-3000 Dressing: A Conservative Treatment for Fingertip Injury. Plastic and Reconstructive Surgery Global Open, 4 (9 Suppl), 2016.

16- Lee L.P., Lau P.Y. and Chan C.W.: A simple and efficient treatment for fingertip injuries. Journal of Hand Surgery, 20 (1): pp. 63-71, 1995.

17- Lee D.H., Mignemi M.E. and Crosby S.N.: Fingertip injuries: An update on management. JAAOS-Journal of the American Academy of Orthopaedic Surgeons, 21 (12): pp. 756-66, 2013.

18- Yeo C.J., Sebastin S.J. and Chong A.K.: Fingertip injuries. Singapore Med. J., 51 (1): pp. 78-86, 2010.

19- Ma G.F., Cheng J.C., Chan K.T., Chan K.M. and Leung P.C.: Finger tip injuries a prospective study on seven methods of treatment on 200 cases. Annals of the Academy of Medicine, Singapore, 11 (2): pp. 207-13, 1982.

20- Van Den Berg W.B., Vergeer R.A., Van Der Sluis C.K., ten Duis H.J. and Werker P.M.: Comparison of three types of treatment modalities on the outcome of fingertip injuries. Journal of Trauma and Acute Care Surgery, 72 (6): pp. 1681-7, 2012.

21- Amer T.A., Enab A.A., El-Nomani S.A. and El-Fayoumy N.M.: Sensory Recovery in Finger Tip Injuries. Egypt J. Neurol. Psychiat. Neurosurg., 47 (2): pp. 325-30, 2010.

22- Ruijs A.C., Jaquet J.B., Daanen H.A. and Hovius S.E.: Cold intolerance of the hand measured by the CISS questionnaire in a normative study population. Journal of Hand Surgery, 31 (5): pp. 533-6, 2006. 